American Journal of Applied Sciences 6 (2): 332-336, 2009

ISSN 1546-9239

(C) 2009 Science Publications

\title{
Promotion of Coconut Shell Gasification by Steam Reforming on Nickel-Dolomite
}

\author{
Pattaraporn Chaiprasert, Tharapong Vitidsant \\ Department of Chemical Technology, Faculty of Science, \\ Chulalongkorn University, Phayathai Rd., Pathumwan, Bangkok 10330, Thailand
}

\begin{abstract}
Biomass gasification by the use of metallic nickel as active metal on dolomite support has been chosen as catalyst because of its activity in biomass steam gasification and tar reduction. The purpose of this study is to study the effects of critical parameters on product gas compositions such as temperature, steam to carbon ratio $(\mathrm{S} / \mathrm{C})$ and oxygen input. The results showed the increasing carbon conversion to gas from $44.13-78.43 \%$ whereas tar was decreased from $19.55-1.4 \%$ at temperature of $800^{\circ} \mathrm{C}$ and S/C 0.95. It is found that Nickel-dolomite is effective for tar reduction and for improving the quality of syngas derived from biomass which is a renewable energy source.
\end{abstract}

Key words: Tar, biomass, gasification, $\mathrm{Ni} /$ dolomite, coconut shell

\section{INTRODUCTION}

Gasification of biomass is a potential source of renewable energy to produce useful gases such as syn gas or pure hydrogen. One of the major issues in biomass gasification is how to deal with the tar formed during the process. Tar is a complex mixture of condensable hydrogen which includes single ring to five ring aromatic compounds along with other oxygen containing hydrocarbons and complex $\mathrm{PAH}^{[5]}$. Tar can be eliminated by thermal cracking or by the use of a catalyst. The catalytic gasification process is an attractive technological alternative to deal with tar and to produce high yield of syn gas. Steam is one of the most commonly used gasification agents because a high percentage of hydrogen can be obtained during the process. Many researchers have proved the usefulness and effectiveness of calcined dolomite and nickel based steam reforming catalysts on decreasing tar yield ${ }^{[3-12]}$. The catalyst can increase the reaction rate of the steam and can participate in the secondary reactions. Therefore, the catalyst improves the quality of the gas product and reduces tar content in the process ${ }^{[6]}$. Besides adding active bed materials also prevents agglomeration tendencies and subsequent coking of the bed. Nickel and dolomite catalysts have been proven to be very active in terms of tar reduction and it shows excellent catalytic activity, resistance of coking and sulfur poisoning ${ }^{[2,9-10]}$. In this experiment, investigations were carried out to determine the efficiency of steam reforming nickel catalyst support on dolomite in a fluidized bed gasifier and to study the effects of some operating parameters on product gas compositions.

\section{MATERIALS AND METHODS}

Feed material: Coconut shell (Thailand) was used as the feedstock with size range 0.75-1.0 $\mathrm{mm}$. The proximate and ultimate analyses of biomass as follows: Moisture $10.53 \%$, fixed carbon $13.10 \%$, volatile matter $57.96 \%$ and ash $18.4 \%$. The ultimate analysis was $\mathrm{C}$ $46.01 \%, \mathrm{H} 6.04 \%, \mathrm{~N} 0.19 \%$ and $\mathrm{O} 47.75 \%$.

Apparatus: The experimental set up, shown in Fig. 1, consists of six main parts: (i) a fluidized bed reactor (ii) biomass feeding section (iii) steam generator and preheating section (iv) cooling section (v) tar collector (vi) gas analysis section. Experiments were carried out in a fluidized bed gasifier with height of $92 \mathrm{~cm}$ and fluidized bed diameter of $10 \mathrm{~cm}$. The cylindrical stainless steel reactor was located inside an electric furnace and controlled by electric heater. At the start up of experimental run, the reactor was charged with $10 \mathrm{~g}$ $\mathrm{Ni} /$ dolomite catalyst as bed material and temperature in the catalytic bed was measured by thermocouple type $\mathrm{K}$. Biomass was continuously fed from screw feeder with feed rate $0.5 \mathrm{~g} \mathrm{~min}^{-1}$. Steam and nitrogen was used as gasifying medium. Water was pumped into the steam generator and flowed to the reactor entrance through a preheating line. When the bed temperature reached the desired level and become steady, the gas product exited

Corresponding Author: Tharapong Vitidsant, Department of Chemical Technology, Faculty of Science, Chulalongkorn University, Phayathai Rd., Pathumwan, Bangkok 10330, Thailand Tel: +66 2218 7523-5 Fax: +662255 5831 
Am. J. Applied Sci., 6 (2): 332-336, 2009

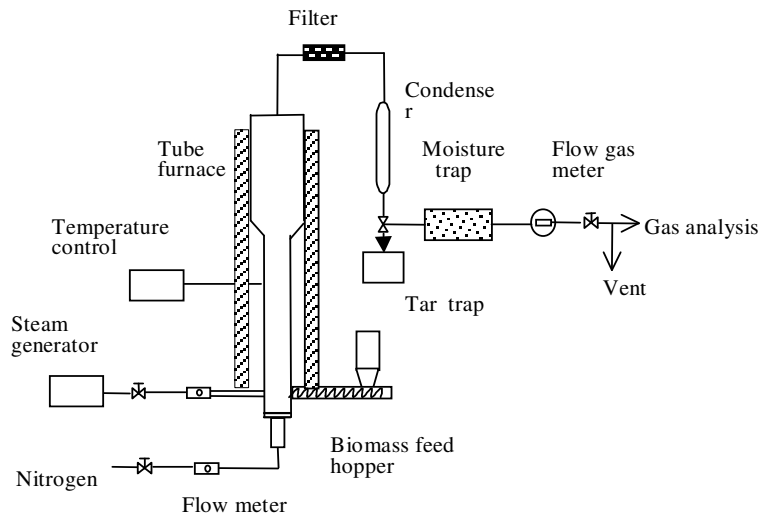

Fig.1: Catalytic biomass gasification process

the reactor. The gas was analyzed after the test run in a stable state. In this experiment, the nitrogen gas was used for fluidization. The minimum fluidization velocity was $12.85 \mathrm{~cm} \mathrm{sec}^{-1}$.

Gas analysis: During reaction, the gaseous product flowed out of the reactor, passed cooling section, moisture trap and finally, the gas filter for drying and cleaning. The exit gases were analyzed by an on-line gas chromatography (Model GC-2010, Zhimadzu, Japan), which is fitted with Unibeads C column ( $3 \mathrm{~m} \times 3 \mathrm{~mm}$ ID) and TCD detectors with helium as carrier to detect mainly gas $\mathrm{H}_{2}, \mathrm{CO}, \mathrm{CO}_{2}$ and $\mathrm{CH}_{4}$.

Catalyst preparation: Nickel-dolomite catalyst was prepared by precipitating of nickel nitrate hexahydrate and calcined dolomite with ammonium carbonate. The filtered catalyst was washed with hot water, dried and calcined to obtain catalysts containing Ni/dolomite. The detail of the preparation of catalyst is described in the previous paper by Srinakruang et al. ${ }^{[9]}$. Before use all catalysts were reduced in $\mathrm{H}_{2}$ at $700^{\circ} \mathrm{C}$.

Characterization of nickel-dolomite catalyst: Catalyst surface area was measured by BET method with $\mathrm{N}_{2}$. The $\mathrm{Ni}$ /dolomite catalyst was analyzed by using the Energy dispersive $\mathrm{x}$-ray fluorescence spectrometer and X-Ray Diffractometer (XRD) at $30 \mathrm{kV}, \quad 30 \mathrm{~mA} \mathrm{Cu} \mathrm{K} \alpha$ radiation and scan speed $0.02^{\circ} \mathrm{min}^{-1}$. The morphology of the catalysts was observed by Scanning Electron Microscopy (SEM) and TEM.

\section{RESULTS AND DISCUSSION}

Characterization of nickel-dolomite: The Nickeldolomite catalyst contains 41.53 wt.\% $\mathrm{CaO}, 14.04$ wt.\% $\mathrm{NiO}, 0.37$ wt. $\% \mathrm{MgO}, 0.25$ wt. $\% \mathrm{Al}_{2} \mathrm{O}_{3}$ and 0.8 wt.\%

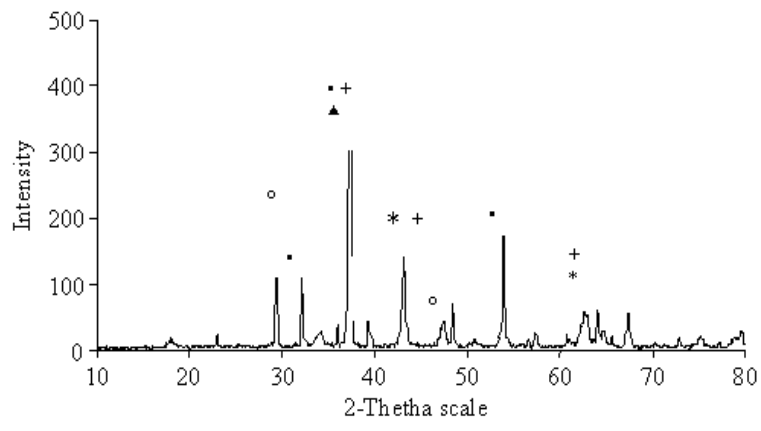

Fig. 2: X-ray diffraction pattern of Nidolomite catalyst (+: $\mathrm{NiO}, \quad *: \mathrm{NiMgO}_{2}, \boldsymbol{\Delta}: \mathrm{MgO}, \quad: \mathrm{CaO}, \circ: \mathrm{CaCO}_{3}$ )
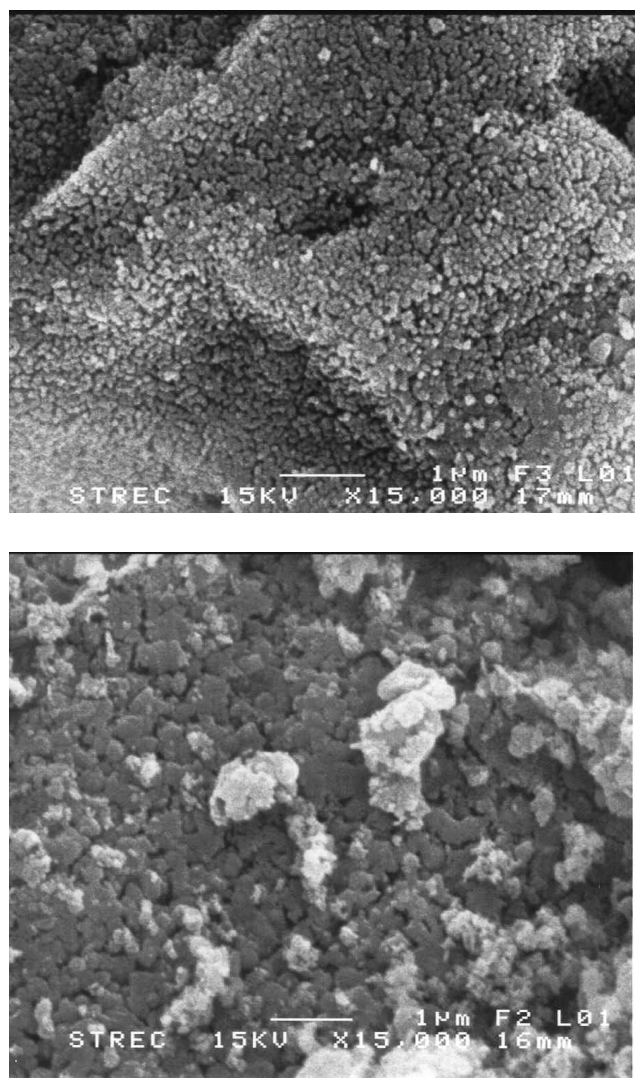

Fig. 3: SEM image of (A): Dolomite support and (B): Nickel-dolomite catalyst

$\mathrm{SiO}_{2}$. The surface area of $\mathrm{Ni} /$ dolomite is $29.22 \mathrm{~m}^{2} \mathrm{~g}^{-1}$. The XRD pattern of $\mathrm{Ni}$ /dolomite catalyst is presented in Fig. 2. The most particular area is situated at $2 \theta$ between 37.3 and $43.2^{\circ}$ characteristic of the cubic $\mathrm{NiO}$ phase. It was observed as $\mathrm{CaCO}_{3}$ at $2 \theta=29.4^{\circ}, \mathrm{MgO}$ at $2 \theta=43.1^{\circ}$ and $\mathrm{MgNiO}_{2}$ at $2 \theta=43.1^{\circ}$.

The SEM of Nickel-dolomite catalyst in Fig. 3 showed porosity of calcined dolomite support and 
Am. J. Applied Sci., 6 (2): 332-336, 2009

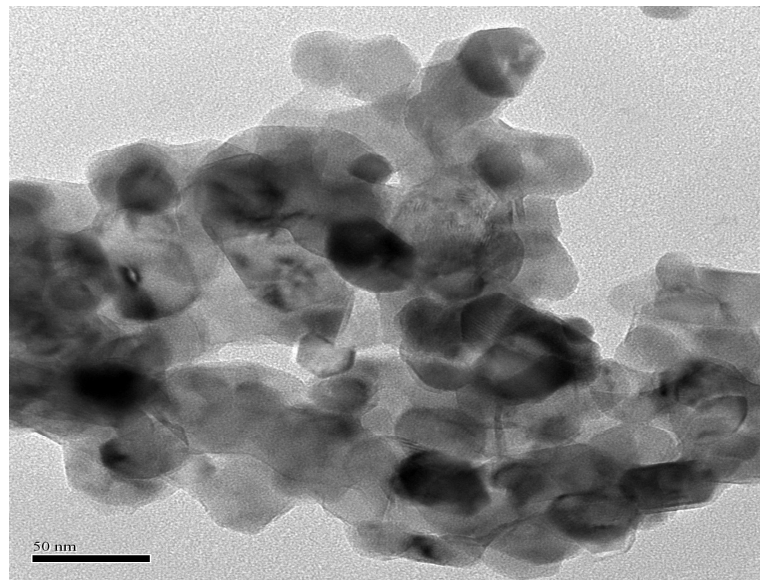

Fig. 4: TEM image of reduced Nickel-dolomite catalyst

deposition of spherical uniform grains of $\mathrm{NiO}$ which can be observed and shown covered on the surface of the support.

From Fig. 4, TEM image of Nickel-dolomite which $\mathrm{NiO}$ has been reduced into nickel $\left(\mathrm{Ni}^{(0)}\right)$ form. Black small particle can be referred to $\mathrm{Ni}$ particles and average diameter is estimated between 4-8 $\mathrm{nm}$ which are observed on the plane of cubic dolomite support.

Effect of catalyst: The influence of catalytic gasification on product gas compositions by using Nickel-dolomite catalyst operated at temperature $800^{\circ} \mathrm{C}, \mathrm{S} / \mathrm{C} 0.95$ and biomass feed rate $0.5 \mathrm{~g} \mathrm{~min}^{-1}$. There is a tendency to increase the $\mathrm{H}_{2}$ content from 22.68-38.74\%, CO content from 32.31-35.72\% and $\mathrm{CO}_{2}$ content from 21.07-29.9\% but $\mathrm{CH}_{4}$ content decreases from $15.11-4.5 \%$ with the use of Nickeldolomite catalyst. In the steam gasification process the presence of Nickel-dolomite causes a significant increase of the $\mathrm{C}_{\text {conv }}$ to gas from $44.13-78.43 \%$ and decreases in char content from $36.21-10.14 \%$ and tar content from $19.55-1.44 \%$ because of tar cracking and steam reforming of hydrocarbon. See following reactions;

$\mathrm{C}_{\mathrm{n}} \mathrm{H}_{\mathrm{m}}+\mathrm{n} \mathrm{H}_{2} \mathrm{O} \stackrel{\text { Ni/Dolomite }}{\longrightarrow} \mathrm{nCO}+\left(\mathrm{n}+\frac{\mathrm{m}}{2}\right) \mathrm{H}_{2}$

$\mathrm{Tar}+\mathrm{H}_{2} \mathrm{O} \rightarrow \mathrm{CO}+\mathrm{H}_{2}$

$\mathrm{CO}+\mathrm{H}_{2} \mathrm{O} \leftrightarrow \mathrm{CO}_{2}+\mathrm{H}_{2}$

Effect of temperature: Temperature is a crucial parameter for the overall biomass gasification process by varying from $600-800^{\circ} \mathrm{C}$. Figure 5 shows that $\mathrm{H}_{2}$

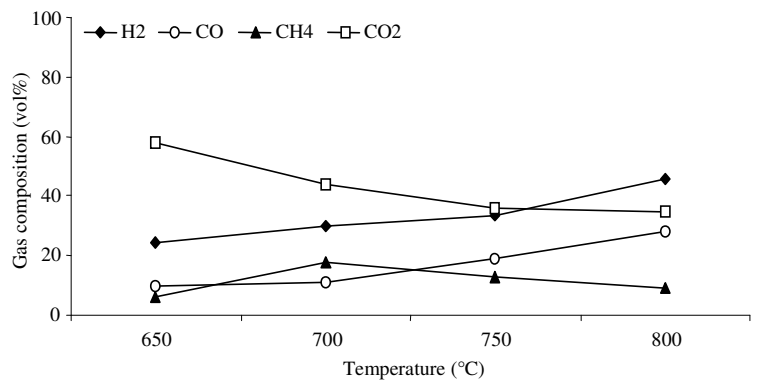

Fig. 5: Effect of temperature on gas composition, S/C 0.95, biomass feed rate $0.5 \mathrm{~g} \mathrm{~min}^{-1}$

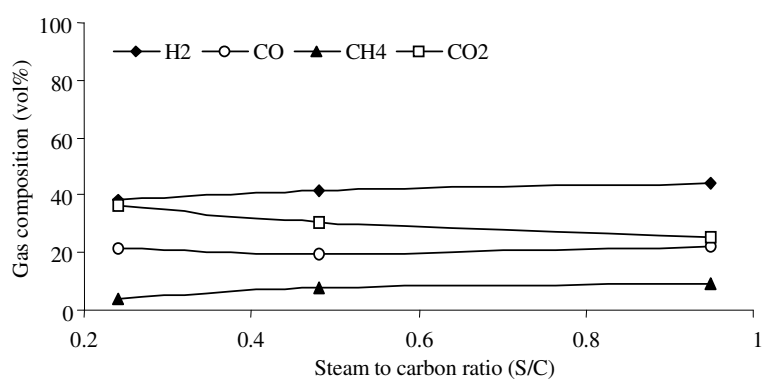

Fig. 6: Effect of steam flow rate on gas composition; temperature $800^{\circ} \mathrm{C}$, feed rate $0.5 \mathrm{~g} \mathrm{~min}^{1}, 10 \mathrm{~g}$ $\mathrm{Ni} /$ dolomite catalyst

and $\mathrm{CO}$ increased with increasing temperature and decreased in $\mathrm{CO}_{2}$ and $\mathrm{CH}_{4}$ compositions. The suitable temperature at $800^{\circ} \mathrm{C}$ showed the best performance catalytic gasification of coconut shell. As temperature increased, more carbon and steam can be converted and favor the products in endothermic reactions (4). Therefore, a higher reforming temperature favor the conversion of tar and $\mathrm{CH}_{4}$ into $\mathrm{H}_{2}$ and $\mathrm{CO}$ and elimination of coke on catalyst decreased in $\mathrm{CO}_{2}$ (5) and (6).

$\mathrm{CH}_{4}+\mathrm{H}_{2} \mathrm{O} \leftrightarrow \mathrm{CO}+\mathrm{H}_{2}$

$\mathrm{C}+\mathrm{H}_{2} \mathrm{O} \leftrightarrow \mathrm{CO}+\mathrm{H}_{2}$

$\mathrm{C}+\mathrm{CO}_{2} \leftrightarrow 2 \mathrm{CO}$

Effect of steam: The steam rate was varied from S/C ratio from 0.2-1.0 while keeping all other conditions constant. The result shows the effect of steam on gas product compositions at temperature $800^{\circ} \mathrm{C}$ in Fig. 6. It can be concluded that an increasing of steam feed results in higher $\mathrm{H}_{2}$ formation, decreased in $\mathrm{CO}_{2}$ and slightly decreased in $\mathrm{CH}_{4}$ because of water gas-shift reaction and methane reforming. 
Am. J. Applied Sci., 6 (2): 332-336, 2009

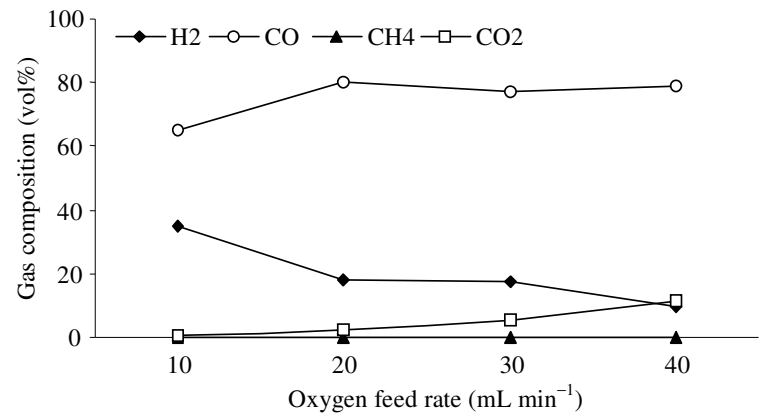

Fig. 7: Effect of oxygen input on gas composition; temperature $800^{\circ} \mathrm{C}$, feed rate $0.5 \mathrm{~g} \mathrm{~min}{ }^{1}, \mathrm{~S} / \mathrm{C} 0.95$ and $10 \mathrm{~g}$ of $\mathrm{Ni} /$ dolomite catalyst

Effect of oxygen addition: Oxygen was varies from $10-40 \mathrm{~mL} \mathrm{~min}^{-1}$ at gasification temperature $800^{\circ} \mathrm{C}$ and S/C 0.95. The result showed that tendency of gas composition increased in $\mathrm{CO}$ and $\mathrm{CO}_{2}$ and were stable because carbon was limiting reactant (7), (8) and (9) in Fig. 7. Hydrogen $\left(\mathrm{H}_{2}\right)$ decreased owing to shift reaction (10). Methane $\left(\mathrm{CH}_{4}\right)$ almost constant with increasing oxygen input. The reaction could be described below:

$\mathrm{C}+\mathrm{CO} 2 \rightarrow 2 \mathrm{CO}$

$2 \mathrm{C}+\mathrm{O}_{2} \rightarrow 2 \mathrm{CO}$

$\mathrm{C}+\mathrm{O}_{2} \rightarrow \mathrm{CO}_{2}$

$\mathrm{CO}_{2}+\mathrm{H}_{2} \leftrightarrow \mathrm{CO}+\mathrm{H}_{2} \mathrm{O}$

The presence of the gasifying agent such as oxygen can promote reactions (2)-(3) and consequently decrease the char formation with increasing oxygen input.

Tar was collected by the trap using 2-propanol and tar component was measured by GC-MS. Tar derived from coconut shell was analyzed and the result is shown in Fig. 8. The main components of tar obtained from non-catalytic gasification were complex polyaromatic hydrocarbons such as dibenzofuran, pyrene, 9 H-fluorene, indene, 11 H-benzofluorene, phenanthrene, methyl anthracene and phenyl napthalene. According to the previous report ${ }^{[4]}$, it has been reported that the main components of tar were aromatic compounds.

Compared with non-catalytic gasification, $\mathrm{Ni}$ catalyst used in catalytic gasification was effective for decreasing the tar level. The tar yield was decreased from 19.55-1.4\%. In Fig. 9, a small concentration of aromatic compounds such as pentanone, diethyl

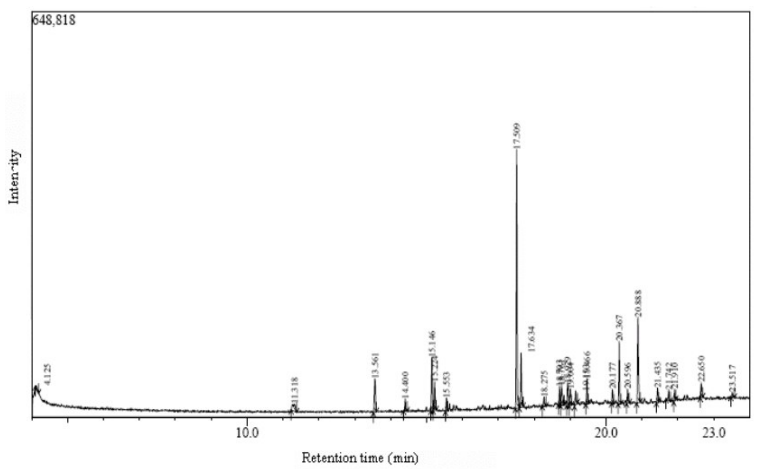

Fig. 8: Tar was collected form non-catalytic gasification

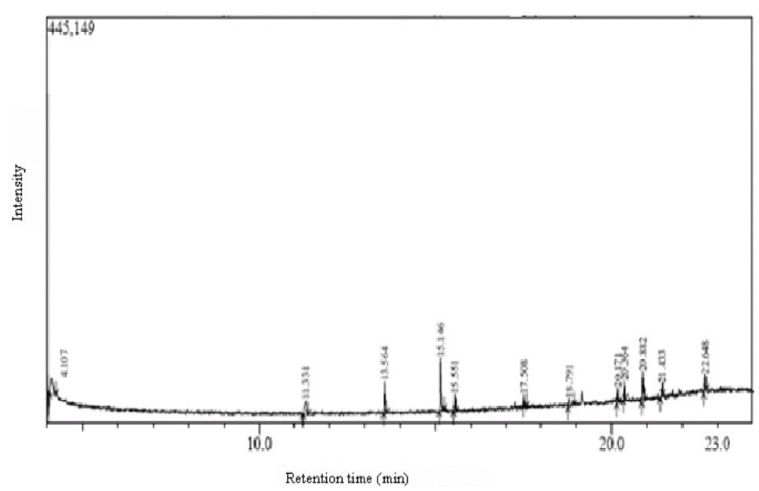

Fig. 9: Tar was collected form catalytic gasification

phathalate, anthracene and pyrene were observed. As reported previously, there will be more than $90 \%$ tar conversion when $\mathrm{Ni}$ catalyst is used at above $700^{\circ} \mathrm{C}^{[9-12]}$.

\section{CONCLUSION}

The Nickel-dolomite catalyst appeared to be an effective catalyst for biomass gasification in a fluidized bed gasifier. The catalyst show high activity for steam reforming of tar and char reduction in the presence of gasifying agent such as steam and oxygen. The suitable conditions operated at temperature of $800^{\circ} \mathrm{C}, \mathrm{S} / \mathrm{C} 0.95$ in by using $\mathrm{Ni} /$ dolomite catalyst. These conditions produce a higher product gas composition of $\mathrm{H}_{2}$ and $\mathrm{CO}$ and lower in $\mathrm{CO}_{2}$ and $\mathrm{CH}_{4}$.

\section{ACKNOWLEDGMENTS}

Financial support was received from the New Energy and Industrial Technology Development Organization (NEDO) of Japan. 


\section{REFERENCES}

1. Arouzo, J., D. Radlein, J. Piskorz and D.S. Scott, 1997. Catalytic pyrogasification of biomass: Evaluation of modified nickel catalysts. Ind. Eng. Chem. Res., 36: 67-75. http://dx.doi.org/10. 1021/ie950271w.

2. Abu El-Rub, Z. and E.A. Bramer, 2004. Review of catalysts for tar elimination in biomass gasification processes. Ind. Eng. Chem. Res., 43: 6911-6919. http://dx.doi.org/10.1021/ie0498403.

3. Baker, E.G., L.K. Mudge and M.D. Brown, 1987. Steam reforming of biomass with nickel secondary catalyst. Ind. Eng. Chem. Res., 26: 1335-1339. http://dx.doi.org/10.1021/ie00067a012.

4. Coll, R., J. Salvado and D. Montane, 2001. Steam reforming model compounds of biomass gasification tars: conversion at different operating conditions and tendency towards coke formation. Fuel Process. Technol., 74: 19-31. ttp://dx.doi. org/10.1016/S0378-3820(01)00214-4.

5. Devi, L. and K.J. Ptasinski, 2003. A review of primary measures for tar elimination in biomass gasification processes. Biomass Bioenergy, 24: 125-140. http://dx.doi.org/10.1016/S09619534(02)00102-2.

6. Garcia, L., M.L. Salvador, J. Arauzo and R. Bilbao, 1999. Catalytic steam gasification of pine saw dust: Effect of catalyst weight/biomass flow rate and steam/biomass ratios on gas production and composition. Energy Fuels, 13: 851-859. http://dx.doi.org/10.1021/ef980250p.
7. Lv, P.M., Z.H. Xiong, J. Chang, C.Z. Wu and Y. Chen, 2004. An experimental study on biomass air-steam gasification in a fluidized bed. Bioresour. Technol., 95: 95-101. http://dx.doi.org/10.1016/j. biortech.2004.02.003.

8. Sutton, D. and B. Kelleher, 2001. Review of literature on catalysts for biomass gasification. Fuel Process. Technol., 73: 155-173. http://dx.doi.org/ 10.1016/S0378-3820(01)00208-9.

9. Srinakruang, J., K. Sato, T. Vitidsant and K. Fujimoto, 2005. A highly efficient catalyst for tar gasification with steam. Catal. Commun., 6: 437-440. http://dx.doi.org/10.1016/j. catcom.2005.03.014

10. Srinakruang, J., K. Sato, T. Vitidsant and K. Fujimoto, 2006. Highly efficient sulfur and coking resistance catalysts for tar gasification with steam. Fuel, 85: 2419-26. http://dx.doi.org/10. 1016/j.fuel.2006.04.026.

11. Wang, T. and J. Chang, 2005. Novel catalyst for cracking of biomass tar. Energy Fuels, 19: 22-27. http://dx.doi.org/10.1021/ef030116r.

12. Wang, T.J., J. Chang, C.Z. Wu and Y. Chen, 2005. The steam reforming of naphthalene over a nickel dolomite cracking catalyst. Biomass Bioenergy, 28: $\quad 508-514 . \quad$ http://dx.doi.org/10.1016/j. biombioe.2004.11.006. 